\title{
Internal Migration and Fertility in Turkey: Kaplan-Meier Survival Analysis
}

\author{
Mehmet Ali Eryurt and İsmet KOÇ \\ Institute of Population Studies, Hacettepe University, 06100 Ankara, Turkey \\ Correspondence should be addressed to Mehmet Ali Eryurt, maeryurt@hacettepe.edu.tr
}

Received 28 December 2011; Revised 17 April 2012; Accepted 14 May 2012

Academic Editor: Shirlena Huang

Copyright (C) 2012 M. A. Eryurt and İ. KOÇ. This is an open access article distributed under the Creative Commons Attribution License, which permits unrestricted use, distribution, and reproduction in any medium, provided the original work is properly cited.

\begin{abstract}
Starting from the mid-twentieth century, Turkey has experienced a remarkable fertility decline. Total period fertility declined from the level of 6 or 7 to the almost replacement level by 2003. Similarly, in the 1950s onwards internal migration gathered speed and transformed Turkey from a predominantly rural country to a mainly urban one in less than half a century. Fertility and migration were mutually reinforcing processes in Turkey. Considering this relationship, the study aims to compare fertility behaviours of migrants with those of nonmigrants at both origin and destination areas. The data source is the 2003 Turkey Demographic and Health Survey. A nonparametric descriptive survival analysis technique, Kaplan-Meier survival analysis, was employed. KaplanMeier survival curves of transition to first, second and subsequent births were compared by migration status. Survival curves of second and subsequent births for rural-to-urban and urban-to-rural migrant women are similar to the curves at the place of destination rather than place of origin. This result reveals that adaptation theory, rather than socialization theory, is more explanatory in the case of Turkey. Kaplan-Meier survival estimates showed that rural native and rural-to-rural migrant women experience all the events related with family formation earlier in their life cycle.
\end{abstract}

\section{Introduction}

Turkey underwent substantial social and economic changes in the last century, especially from 1950 onwards. Starting in the 1950s, internal migration and urbanization gathered speed and became one of the most important factors changing social and economic structure of Turkey. The results of 2003 Turkey Demographic and Health Survey [1] reveal that urban population exceeded 71 percent of the total population, transforming Turkey from a predominantly rural country to a mainly urban one in less than half a century. Similarly, Turkey experienced a serious fertility decline starting in the 1950s. Until the 1970s, the decline was gradual, but since that time the country experienced a steeper decline. During this process of change, the level of total period fertility declined from a level of 6 or 7 to a value near to replacement level by the 2000s. Moreover, the 2003 Turkey Demographic and Health Survey [1] shows that in three of the five demographic regions, namely in the West, the Central, and the North Anatolia regions, the total fertility rate is below the replacement level. Changes in fertility and migration occurred simultaneously as mutually reinforcing processes in Turkey.

There are relatively few studies on the reproductive behaviour of internal migrants, not only in Turkey but also in all over the world. Moreover, most of the existing studies, particularly the recent ones, focus on the fertility of immigrants in industrialized countries. In addition, most of the studies on the fertility of internal migrants focus only on one type of flow, from rural-to-urban. Other migration flows such as urban-to-urban, urban-to-rural, and ruralto-rural, are generally dis- regarded. Considering all migration flows, this study aims to compare fertility behaviours of migrants with those of non- migrants, at both origin and destination areas. Specifically, the study examines whether reproductive behaviour changes when people migrate from one sociospatial context to anoth- er within Turkey.

In the literature, we face two main hypotheses explaining differences in fertility between nonmigrants and different groups of migrants. Socialization hypothesis posits that 
fertility behaviours are formed during childhood and that they remain relatively stable throughout life; hence, those who arrive in a culturally different setting as adults adapt slowly to the new reproductive norms that are prevalent there [2-9]. Convergence towards the fertility levels of new cultural setting occurs only in the next generation. On the other hand, adaptation hypothesis emphasizes the importance of current, rather than the childhood residence [10-15]. This hypothesis supports the possibility of resocialization of migrant populations. It assumes that migrants adjust their fertility in response to the costs and opportunities they encounter in their new environment. Dominant values and norms related to family and fertility in the new setting shape the migrant's fertility behaviour, regardless of where the migrant originally came from. The main difference between the socialization and adaptation hypotheses lies at the length of time within which social and economic factors are presumed to operate. While socialization hypothesis assumes that adjustment to the fertility of receiving society occurs after a generation, in the adaptation hypothesis, it is thought to occur within less than ten years [15]. This study attempts to identify which of these two hypotheses is more explanatory in the case of Turkey by employing a nonparametric descriptive survival analysis technique, Kaplan-Meier survival analysis. KaplanMeier survival curves of transition to first, second, third, and fourth birth will be compared by migration status of the mother.

\section{Internal Migration and Fertility in Turkey}

The history of internal migration and fertility in Turkey can be presented in three stages. The first period is between 1923 and 1955, the second period covers the period of 1955 to 1980, and the period starting from 1980 onwards is the third period.

When the Turkish Republic was founded in October 1923 immediately after a long period of war to rebuild social and economic life, it was necessary to overcome the loss of population. During the early years of the Republic, the economy was mainly dependent on agriculture, approximately 75 percent of the population of approximately 13 million, was living in rural settings (Table 1). State-led industrialization was creating new employment opportunities in cities, but at a speed which matched the population growth of the cities without the need of significant amount of migration [16]. The 1923-1955 period can be considered a relatively stable period regarding internal migration. The share of urban population remained nearly the same, fluctuating between 24 percent and 25 percent during this period. Due to the lack of the population, especially a shortage in the labor force, from the foundation of the Republic to the beginning of the sixties, the population policy of Turkey was directed toward population growth. The quantity of the population was seen as the source of national power. To increase the population, fertility rates should be increased, health services should be expanded to decrease mortality rates, and immigration should be encouraged. All of these policy approaches during this period were taken by national governments. The rationale of the pronatalist policies of this period was that population growth had a positive impact on economic development. Partially due to the population policies of the period, but largely as a consequence of the demands of economic and social rebuilding process, the population of the country increased. Between 1923 and 1955, the population almost doubled, increasing from 13 to 24 million. Life expectancy at birth increased from 35 years to 45 years, and fertility increased significantly from around 5.5 children to 7.0 children during this period. Fertility rates fluctuated between 7.0 and 6.5 until the permanent decline of fertility began in the 1950s.

The second period of Turkey's demographic history started with the population growth rate at its highest level, 2.8 percent per year (Table 1). In the first five year development plan, it was argued that the growth in gross national product (GNP) was undermined by the fast population growth rate. It was felt that there was a necessity to bring population growth under control. Accordingly, a law on population planning was prepared and enacted. The population planning law of 1965 has indicated a turning point in terms of population policies of the Turkish Republic. Until that time except for condom, all contraceptives were illegal and pronatalist population policies were in force. The prohibition of contraceptives under the $1936 \mathrm{H} \imath$ fzıss $t$ hha law was lifted. The law also stated strict conditions for abortion and sterilisation that would be allowed only for sound medical reasons [20-23]. As a result of these developments, starting from 1950s fertility began to decline and it did not reverse again. On the economic front, the emphasis was on rapid industrialisation. The import-substitution economic policy of the period required more labor power in urban sectors, especially in industry. After a period of rapid expansion of cultivable land, the cultivatable land reached its limits, and excess of the population in rural areas flowed to the cities. The internal migration of this period was mainly a labor migration directed from rural-to-urban areas.

Until the 1970s, rural-to-urban migration was the main direction of migration flow. However, starting from the end of the 1970s, urban-to-urban migration became the major direction of migration flow [24-26], (Table 2). However, rural-to-urban migration continued to increase the urban population, and the share of urban population exceeded 45 percent by the beginning of 1980s (Table 1).

In spite of the fertility decline, the population continued to grow during this period due to the fact that decline in fertility rates was still behind the decline in death rates. Life expectancy at birth was still around 60 years at the beginning of 1980s and the population doubled from 24 to 45 million between 1955 and 1985 .

During the third stage of demographic history of Turkey, after the military coup of 1980 the new constitution of Turkey took up the concept "family planning" for the first time in the history of the Turkish constitution. In May 1983, just half a year after the adoption of the constitution, the first antinatalist law was revised and a more liberal and comprehensive one was accepted. In this way, abortion and sterilization were legalized. The distinctive property of the third stage of demographic transition in Turkey was a 
TABLE 1: Urban-rural population and total fertility rates of Turkey: 1927-2010 period.

\begin{tabular}{|c|c|c|c|c|c|c|c|}
\hline $\begin{array}{l}\text { Census } \\
\text { year }\end{array}$ & $\begin{array}{l}\text { Total population } \\
\text { (thousand) }\end{array}$ & $\begin{array}{l}\text { Annual growth } \\
\text { rate }(\% 0)\end{array}$ & $\begin{array}{l}\text { Percent of urban } \\
\text { population (\%) }\end{array}$ & $\begin{array}{l}\text { Growth rate of urban } \\
\text { population }(\%)\end{array}$ & $\begin{array}{c}\text { Total } \\
\text { fertility } \\
\text { rate }\end{array}$ & $\begin{array}{l}\text { Life expectancy } \\
\text { at birth }\end{array}$ & $\begin{array}{c}\text { Infant mortality } \\
\text { rate }(\%)\end{array}$ \\
\hline 1927 & 13,648 & - & 24.2 & & & & \\
\hline 1935 & 16,158 & 21.1 & 23.5 & 2.5 & 6.7 & 35.4 & 273 \\
\hline 1940 & 17,821 & 17.2 & 24.4 & 3.2 & 6.6 & 31.3 & 274 \\
\hline 1945 & 18,790 & 10.6 & 24.9 & 1.4 & 6.9 & 38.1 & 255 \\
\hline 1950 & 20,947 & 21.7 & 25.0 & 1.9 & 6.9 & 43.5 & 224 \\
\hline 1955 & 24,065 & 27.8 & 28.8 & 7.2 & 6.5 & 44.6 & 189 \\
\hline 1960 & 27,755 & 28.5 & 31.9 & 6.0 & 6.1 & 49.9 & 169 \\
\hline 1965 & 31,391 & 24.6 & 34.4 & 5.0 & 5.6 & 53.1 & 151 \\
\hline 1970 & 35,605 & 25.2 & 38.5 & 6.1 & 5.1 & 55.1 & 139 \\
\hline 1975 & 40,348 & 25.0 & 41.8 & 5.4 & 4.3 & 57.0 & 134 \\
\hline 1980 & 44,737 & 20.7 & 43.9 & 3.9 & 4.1 & 59.0 & 95 \\
\hline 1985 & 50,664 & 24.9 & 53.0 & 4.8 & 3.0 & 64.9 & 78 \\
\hline 1990 & 56,473 & 21.1 & 59.0 & 4.1 & 2.6 & 67.4 & 53 \\
\hline 2000 & 67,804 & 18.3 & 64.9 & 3.2 & 2.1 & 71.0 & 43 \\
\hline 2010 & 73,723 & 13.0 & 76.3 & 1.7 & 2.1 & 74.3 & 17 \\
\hline
\end{tabular}

Source: SIS, 2000 [17]; Koç et.al., 2010 [18]; TURKSTAT, 2012 [19].

TABle 2: Migration flows in Turkey during 1975-2000 period.

\begin{tabular}{|c|c|c|c|c|}
\hline Place of origin and destination & $1975-1980$ & 1980-1985 & 1985-1990 & 1995-2000 \\
\hline Urban-to-urban & 48.9 & 56.2 & 62.2 & 57.8 \\
\hline Rural-to-urban & 17.0 & 22.5 & 18.0 & 17.5 \\
\hline Urban-to-rural & 19.3 & 12.8 & 12.6 & 20.1 \\
\hline Rural-to-rural & 14.8 & 8.5 & 7.3 & 4.7 \\
\hline Total & 100.0 & 100.0 & 100.0 & 100.0 \\
\hline
\end{tabular}

Source: TURKSTAT, 2000 [27].

definite and irreversible decline in the population growth rate (Table 1). During this period the downward trends of fertility and mortality continued. By the beginning of the 2000s, life expectancy at birth exceeded 71 years, infant mortality rates decreased 17 per thousand, and total fertility rate decreased almost to the replacement level. During this period, the weight of urban-to-urban migrations continued to increase in the volume of internal migration $[25,26]$. The share of urban-to-urban migration decreased a little bit during the period of 1995-2000 probably due to forced migrations from the eastern villages to urban centers of the country [28]; however, this exceptional period does not change the general trends of migration flows. As is the case worldwide, the causes of migration started to vary and became complicated. During this period, socioeconomic, cultural, and political factors became influential and new migration types emerged. The share of circular, temporary, and seasonal migrations increased during this period [29].

\section{Data Source and Methodology}

The data used in this study comes from the Turkey Demographic and Health Survey, 2003 (TDHS-2003). The survey aimed to provide information on the socioeconomic characteristics of households and women, family planning trends and levels in fertility, infant and child mortality, marriage patterns, maternal and child health, nutritional status of women and children, and reproductive health. The fieldwork of the TDHS-2003 was conducted by Hacettepe University, Institute of Population Studies, between December 2003 and May 2004. TDHS-2003 is a nationally representative survey of 10836 households and involved 8075 eligible women, defined as ever-married women aged 15 to 49 who generally lived in the household or visited the household in the night before the interview. Two types of questionnaires were employed for data collection in TDHS-2003, namely, "household" and "ever-married" questionnaires, with faceto-face interviews. Some background information on nevermarried women was collected with a separate module included in this section. The sample of the survey was designed with a weighted, multistage, stratified cluster sampling approach. The sample was designed to provide an estimation of demographic and health indicators for Turkey as a whole, for urban and rural areas, for the five demographic regions of the country (west, south, central, north and east), and for the 12 geographical sub-regions (NUTS 1). 
TABLE 3: Sample composition for migration status variable, TDHS2003.

\begin{tabular}{lc}
\hline Migration status & Number of subjects \\
\hline Urban native & 1796 \\
Urban-to-urban migrant & 1405 \\
Urban-to-rural migrant & 284 \\
Rural-to-urban migrant & 1731 \\
Rural-to-rural migrant & 638 \\
Rural native & 1861 \\
\hline Total & 7715 \\
\hline
\end{tabular}

The information on fertility used in the study is based on retrospective reproductive histories of women age 15-49 interviewed in the TDHS-2003. Each woman was asked for a history of all her births, including the month and year of each.

In the TDHS-2003, there are questions about childhood place of residence, place of previous residence, and number of years the respondents spent in the current place of residence. In analyzing the migration status of the women, these variables were used to construct the migration status variable. To avoid anticipatory analysis, migration status at the beginning of the observation, that is, at the marriage, at the first birth, at the second birth, and at the third birth, has been taken as a fixed characteristic. The migration status variable included six categories. If the respondent's current place of residence was urban and duration at the current residence has been reported as "always" by the respondent, the woman is categorized as "urban native". In the opposite situation if the women's current residence was rural and duration of residence in this place has been reported as "always", the women is put into "rural native" category. If the last migration occurred before marriage (or first birth for the analysis of transition to second birth and second birth for the analysis of transition to third birth), migrations status of the women were decided comparing previous place of residence and current place of residence. If the previous place of residence was urban and current place of residence was also urban, the woman is put into the "urban-to-urban migrant" category. If the previous place of residence was urban and current place of residence was rural, the woman is labelled as "urban-to-rural migrant". If previous place of residence was rural and current place of residence was urban, the woman is classified as "rural-to-urban migrant". And if the previous place of residence was rural and current residence was also rural, the women is treated as "rural-to-rural migrant". If the last migration took place after a previous event (i.e., marriage, first birth, second birth etc.), in this case childhood place of residence and previous place of residence were compared with the same logic. In cases where they are different, women were put into the relevant migrant category and treated as nonmigrant, if both childhood and previous place of residences are the same (Table 3 ).

In this study, the method of analysis is Kaplan-Meier survival analysis. The Kaplan-Meier method is used to describe fertility events, such as transition to first, second, third, and fourth birth in Turkey according to migration status. Life table and Kaplan-Meier techniques are useful tools to analyze the time it takes for the transition from one parity to the next. In addition, these techniques can produce correct estimates of the proportion of women who have a subsequent birth at a successive duration of exposure. If the observation duration is long enough, the proportion of women who have a subsequent birth after a given duration is similar to the parity progression ratio from one parity to the next [30-32]. Thus, these techniques are more sensitive to measure changes in reproductive behaviour compared with conventional fertility measures, such as the TFR. These techniques may provide more detailed information about the cause of fertility decline. Using these techniques, we can learn whether fertility change is due to the spacing of births or due to a change in the proportion of women reaching high parities. In sum, life table analyses of parity orders may provide information both on quantum and tempo of fertility.

In this section, we preferred to use Kaplan-Meier technique instead of life table technique, because it is more advantageous compared with ordinary life table technique. In the Kaplan-Meier approach, it is not necessary to group episode durations according to arbitrarily defined time intervals. Instead, the Kaplan-Meier method is based on the calculation of a risk set at every point in time where at least one event occurred [33]. In this way, the information contained in a set of episodes is optimally used. Another difference between the life table method and the Kaplan-Meier method is related to the contribution of censored cases to the exposure. Kaplan-Meier technique can cope with the right censoring issue better than ordinary life table technique [34]. If no censoring occurs, the Kaplan-Meier method gives the same result as the life table method. In the life table method, it is assumed that censoring occurs in the middle of the time interval. However, in the Kaplan-Meier method censoring is assumed to occur after the time point for which the survival function is estimated, and, thus, censored cases contribute more to the exposure. The only disadvantage of this approach is that all episodes must be sorted according to their ending and starting times. Advanced statistical programs can easily overcome this problem with efficient sorting algorithms [33].

The Kaplan-Meier method estimates for all "event times", $t_{i}$, and can be calculated according to formula below:

$$
S\left(t_{i}\right)=\prod_{l=1}^{i} \frac{n_{l}-d_{l}}{n_{l}},
$$

where $n$ is the number of individuals at risk at time $t_{i}$, and $d_{l}$ is number of events at time $t_{i}$.

\section{Findings}

4.1. Fertility Levels, Patterns, and Trends. The objective of this section is to examine both current and cumulative fertility levels, patterns, and trends by migration status. The level of fertility is given by the total fertility rate, which pertain to three-year period preceding the survey. The three-year period was chosen for calculating these rates to provide the most current information, to reduce sampling error, and to avoid problems of displacement of births. The pattern of fertility 
is given by the age-specific fertility rates. The mean number of children ever born to women age 40-49 represents the childbearing experience of a real age cohort and reflects mainly the past fertility behavior. The fertility trend is given by comparing the number of children ever born and total period fertility rates (Table 4).

The total fertility rate indicates that if fertility rates were to remain constant at the level prevailing during the threeyear period before the TDHS-2003, a woman in Turkey would bear 2,23 children during her lifetime. The TFR for women age 15-49 ranges from 1,68 among urban native women to 3,63 among rural-to-rural migrant women. The highest TFRs are observed among rural-to-rural and urbanto-rural migrants, and the lowest TFR is observed among urban natives and urban-to-urban migrants.

The age-specific fertility rates presented by migration status show that women in Turkey experience their prime reproductive years during their twenties. At every age group, rural-to-rural migrant women and urban-to-rural migrant women bear more children than urban women. We observed higher fertility rates among urban-to-rural, ruralto-urban, and rural-to-rural migrant women, especially in the youngest age group. It is known that in the youngest age group, the fertility rate is largely affected by the age at which women marry. The urban native and urban-to-urban migrant women's age-specific fertility rates assume a more gradual pattern, an indication both of delayed marriage and some deliberate attempt to postpone or terminate births by these women.

Children Ever Born is a kind of cumulative measure of childbearing. This measure of lifetime fertility reflects the accumulation of births over the past 30 years and, therefore, its relevance to the current situation is limited. In general, the mean number of children ever born is calculated for currently married women aged between 40 and 49 years since by these ages most of them already completed their fertility. Table 4 shows that on average, a woman in Turkey has given birth to 3.63 children by the end of reproductive ages. Ruralto-rural migrants and rural natives have the highest mean number of children ever born, and urban natives and urbanto-urban migrants have the lowest mean number of children.

A comparison of the measure of completed fertility, mean number of children ever born with the measure of current fertility, and the total fertility rate give a rough indication of the trend in fertility over time. If fertility is stable over time in a population, the TFR and the mean CEB for women aged 40-49 are expected to be similar. If fertility levels have been falling, the TFR will be substantially lower than the mean CEB among women aged 40-49. The comparison of the TFR with the mean CEB reveals that fertility has fallen sharply in Turkey over the past several decades. The difference between the mean CEB and the TFR is 1.4 children. Interestingly, the largest implied decline in fertility by migration status is observed among rural natives ( 2 children). The difference is around one child, among other categories of migration status variable.

A closer look to the absolute number of children in Turkey by migration status may provide further insight into the issue (Figure 1). The analyses were restricted to women aged between 40 and 49 years, since by these ages most of them already completed their fertility. Looking at the distribution of the family size of women between 40 and 49 years, it can be seen that the percent of childless women is very low in all of the categories. The difference between categories starts to be visible when we look at the women with only one child. Urban-to-urban migrants and urban natives are highest percentage with 10.7 and 10.2, respectively. Rural-to-urban migrants follow them and rural-torural migrants, rural natives, and urban-to-rural migrants have the lowest percentages. The same order can also be observed for the women with 2 children. Large differences remain between the categories for the mothers with at least four children. Only 20 percent of the urban native or urbanto-urban migrant women have four or more children, whereas this proportion climbs above 51 percent for rural native, rural-to-rural or urban-to-rural migrant women. The percentage of rural-to-urban migrant is 45 percent.

4.2. Kaplan-Meier Survival Estimates. In this section, Kaplan-Meier survival estimates of the transition from the first marriage to the first birth, and subsequently to the second, third, and fourth birth will be presented.

Here, Kaplan-Meier survival estimates will be calculated by birth order, based on single months. The equality of survivor functions within each covariate will be tested using the logrank test. The logrank test is a hypothesis test to compare survival distributions of the two samples. It is a nonparametric test and appropriate to use when the data are right censored. The logrank test compares estimates of the hazard functions of the two groups at each observed event time. It is constructed by computing the observed and expected number of events in one of the groups at each observed event time and then adding these to obtain an overall summary across all time points where there is an event [35-37].

4.2.1. The Transition to First Birth. The onset of childbearing has important impact on fertility both at the individual and the societal level. The timing of first birth determines the timing of subsequent births and has also strong impact on overall fertility level. As childbearing out of marital unions are negligible in Turkey, there is a strong association between age at first marriage and age at first birth. The postponement of first births reflects a rise in age at marriage and contributes largely to the emergence of the current overall fertility level. The first birth marks a woman's transition into motherhood and has important implications for the status of women both at familial and societal level. In traditional Turkish patriarchal society, a newly married woman needs to bear a child, especially a son, as soon as possible to establish her status in her husband's family.

First it is useful to look at the picture at the national level. Figure 2 confirms the fact that first birth is almost a universal event in Turkey. The majority of women (73 percent) have their first births within 2 years of their first marriage. More than 9 women out of 10 become mothers within 5 years after marriage. The percent of childless women decreases to a value below 5 percent within 10 years after marriage and at 
TABLE 4: Total age-specific fertility rates for three years preceding the survey and mean number of children ever born, by migration status, TDHS-2003.

\begin{tabular}{|c|c|c|c|c|c|c|c|}
\hline Mother's age at birth & Urban native & $\begin{array}{c}\text { Urban-to-urban } \\
\text { migrant }\end{array}$ & $\begin{array}{l}\text { Urban-to-rural } \\
\text { migrant }\end{array}$ & $\begin{array}{c}\text { Rural-to-urban } \\
\text { migrant }\end{array}$ & $\begin{array}{l}\text { Rural-to-rural } \\
\text { migrant }\end{array}$ & Rural native & Turkey \\
\hline $15-19$ & 27 & 28 & 117 & 104 & 144 & 27 & 44 \\
\hline $20-24$ & 88 & 135 & 209 & 179 & 239 & 117 & 126 \\
\hline $25-29$ & 113 & 117 & 127 & 151 & 163 & 158 & 126 \\
\hline $30-34$ & 61 & 68 & 86 & 84 & 91 & 102 & 71 \\
\hline $35-39$ & 42 & 28 & 71 & 32 & 56 & 37 & 33 \\
\hline $40-44$ & 4 & 10 & 8 & 14 & 17 & 17 & 11 \\
\hline $45-49$ & 0 & 0 & 0 & 0 & 16 & 0 & 0 \\
\hline TFR (women 15-49) & 1.68 & 1.93 & 3.09 & 2.82 & 3.63 & 3.28 & 2.23 \\
\hline Mean CEB (women 40-49) & 2.97 & 2.85 & 4.15 & 3.89 & 4.45 & 4.43 & 3.63 \\
\hline
\end{tabular}

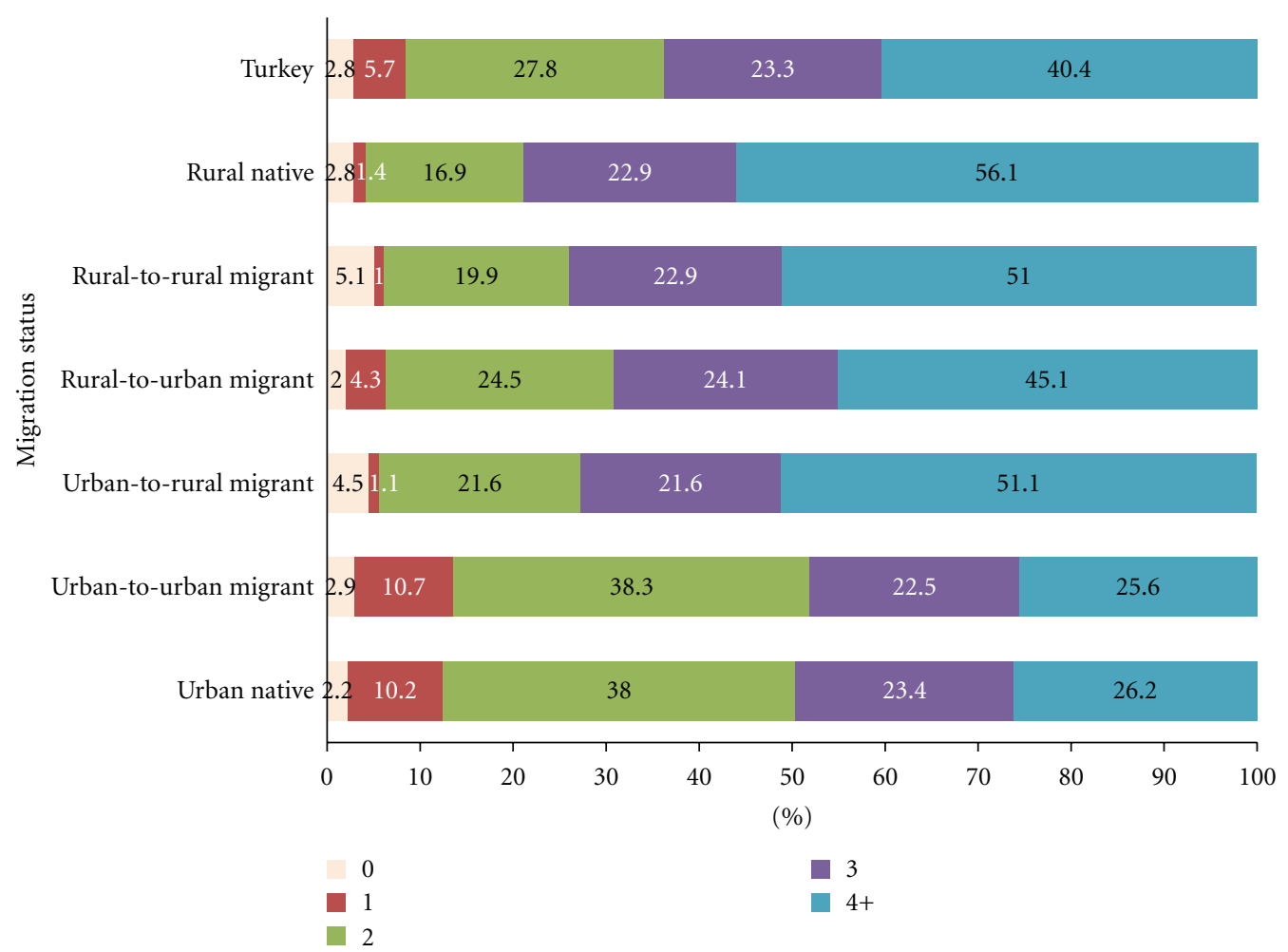

FIGURE 1: Percent distribution of total children ever born in Turkey by migration status (women 40-49), TDHS-2003.

the end of reproductive ages just 1 percent of married women remain childless, most probably due to sterility. The median first birth interval in Turkey is measured as 15.9 months (Table 5). In other words, half of the women in Turkey have their first births within 15.9 months of their first marriage. In Turkey, most women get pregnant very soon after their first marriage.

These results are also consistent with the low prevalence of contraceptive use before first births. Seventy-six percent of ever-married women did not use any contraceptives before their first births in Turkey. After having first births, half of the ever-married women started to use contraceptives [1]. Another indicator of the extensity of first births among women in Turkey is the desire to limit childbearing. While just 1.5 percent of currently married childless women did not want to have a child, the percentage of currently married women who want no more children increases to 26 percent among women who have one living child and increases to 81 percent among women who have two living children [1].

Regarding the pattern of the survival curves, it can be said that the timing of first births does not differentiate according to women's migration status. The result of logrank test also shows that survival curves by migration status are not different. Since the patterns of all survival curves resemble each other, the figure of survival curves for first birth is not given here.

The median first birth intervals by migration status range from 15.1 months among urban natives to 16.6 months 
TABle 5: Median duration of transition to first, second, third, and fourth births by migration status. Kaplan-Meier survival curve estimates.

\begin{tabular}{lcccc}
\hline & First birth & Second birth & Third birth & Fourth birth \\
\hline Urban native & 15.1 & 37.5 & 70.1 & 112.0 \\
Urban-to-urban migrant & 15.6 & 44.2 & 44.8 & 100.1 \\
Urban-to-rural migrant & 16.3 & 28.3 & 53.0 & 40.6 \\
Rural-to-urban migrant & 15.8 & 31.7 & 32.7 & 57.4 \\
Rural-to-rural migrant & 16.6 & 25.8 & 31.9 & 35.2 \\
Rural native & 16.3 & 25.9 & 50.5 & 33.0 \\
Turkey & 15.9 & 32.2 & 47.7 \\
\hline
\end{tabular}

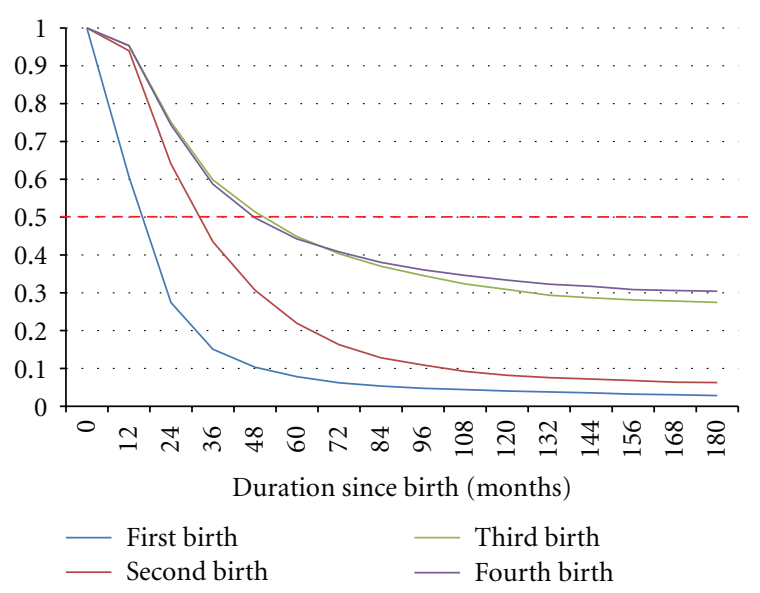

Figure 2: Kaplan-Meier survival estimate of the proportion of having first, second, third, and fourth births since previous birth, Turkey 2003.

among rural-to-rural migrants (Table 5). Interestingly urban native women have the shortest median first birth interval. We can hypothesize that these women marry later than the women in the other categories, and shorter first birth interval may be a compensation for the time "wasted" by delaying marriage [38]. Unstable conditions at the early stage of family building process may be a reason for higher median first birth intervals among rural natives and migrants. It is more common for a new married couple to live with husband's family until they can afford a separate house. However, in urban areas nuclear families are more common as initial family type. Therefore, we may argue that urban native women afford expenditures of the child earlier than the others.

4.2.2. The Transition to Second Birth. In this section, the impact of migration status and other covariates on transition from first to second child will be investigated. During last five years the total fertility of Turkey declined almost 15 percent: from 2.61 to 2.23 [1]. The decline, especially in some subpopulation groups is significant. In rural areas, total fertility is still 2.65 children per woman, but in urban areas it is already below replacement at 2.06. Women having completed secondary or higher education are almost at the lowest low fertility level (1.39). These fertility rates indicate a turning point for Turkey and make a detailed analysis of the transition to second birth meaningful. At the national level, Kaplan-Meier survival estimates reveal that 36 percent of one child mothers have their second child within 2 years following their first birth (Figure 2).

Within five years following the first birth, 78 percent of one child mothers have their second child. The percent of women having a second child increases to 92 percent by the end of 10 years following the birth of first child. Six percent of women do not have second child by the end of their reproductive ages. The median second birth interval in Turkey is 36 months (Table 5). That is to say, half of the one child mothers in Turkey have their second child within 2.5 years following their first birth.

Figure 3 provides evidence for differential fertility behaviour by migration status. There is a significant similarity between the survival curves of rural natives and ruralto-rural migrants and those of urban natives and urban-tourban migrants. While the curve of urban-to-rural migrant is more similar to the pattern at place of destination, ruralto-urban migrants reflect the pattern of both place of origin and destination apportioning the graph.

Considering the pattern of the survival curves by migration status (Figure 3), it is seen that almost half of the rural native and rural-to-rural migrant women have their second child within 2 years following the birth of first child, this percentage decreases to less than 30 percent among urban natives and urban-to-urban migrant women. Sixty three percent of rural-to-urban migrant women and 58 percent of urban-to-rural migrant women have their second child within 2 years. These percentages are closer to the percentages at the place of destination rather than place of origin. Five years after the first child is born, the percentage of women having a second child among urban native and urban-to-urban migrant women is around 70 percent, whereas this percentage increases to almost 90 percent for rural native and rural-to-rural migrant women. After the first five years, however, the gaps between the curves start to narrow, although different behaviors by migration status continue to persist. At the end of 10 years following the first birth, 14 percent of urban-to-urban migrant women and 11 percent of urban native women do not have second child. This percentage decreases to 3 percent among rural natives and 4.6 percent among rural-to-rural migrants. The percentage of women who do not have second child within 10 years among rural-to-rural migrant women is closer to 


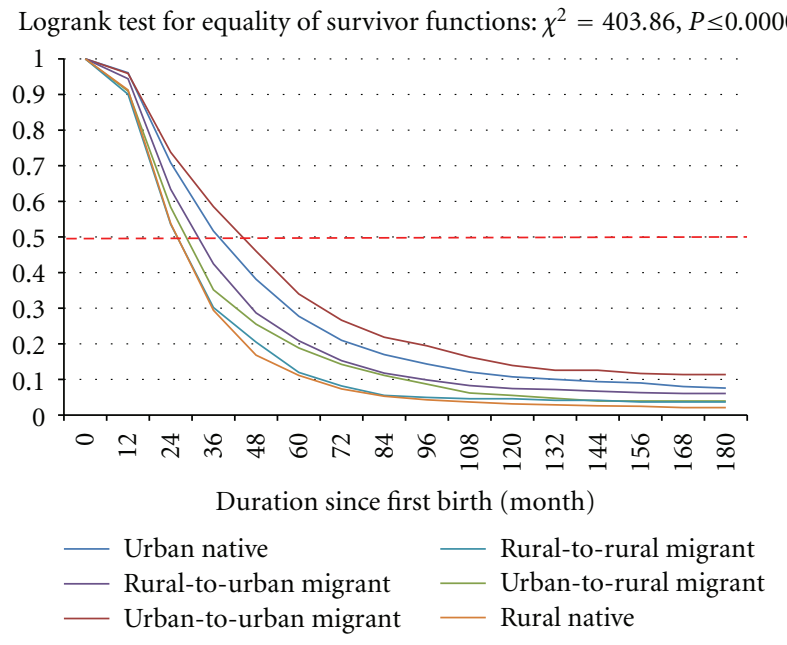

FIgURE 3: Kaplan-Meier survival estimate of the proportion of having second birth since first birth, by migration status.

the percentage of urban native and percentage of urban-torural migrant women is closer to the percentage of rural natives. By the end of reproductive ages, 7 percent of urban natives, 10 percent of urban-to-urban migrants, 4 percent of urban-to-rural migrants, 6 percent of rural-to-urban migrants, 4 percent of rural-to-rural migrants and 2 percent of rural natives do not have second child. The median second birth interval is highest among urban-to-urban migrants (44 months) and lowest among rural-to-rural migrants and rural natives (26 months).

4.2.3. The Transition to Third Birth. The transition from second to third birth is a critical component of the fertility decline during the demographic transition, since the reduction in third and higher order births maintains the fertility decline $[39,40]$. The results of the 2003 Turkey Demographic and Health Survey have shown that more than half of the currently married women (57 percent) stated two children as the ideal number of children. The spread of the two child norm in the society can also be seen looking at the percentage of two-child mothers who want to have a third child in the future. According to the results of TDHS-2003, just 12 percent of two-child mothers want to have a third child in the future [1]. As the two-child norm spreads in society, the transition to the third child represents the threshold level in terms of fertility transition.

Kaplan-Meier survival estimates show that at the national level 25 percent of two-child mothers have their third child within 2 years after their second birth (Figure 2). The percentage of women having a third child increases to 55 percent within 5 years and 10 years after the birth date of the second child the percentage having a third child rises to 69 percent. By the end of reproductive ages 27 percent of two child mothers do not have an additional child. The median third birth interval is estimated as 51 months (Table 5).

Kaplan-Meier survival estimates of third birth by migration status are displayed in Figure 4. Similar to the second birth, urban-to-urban migrants and urban natives have their

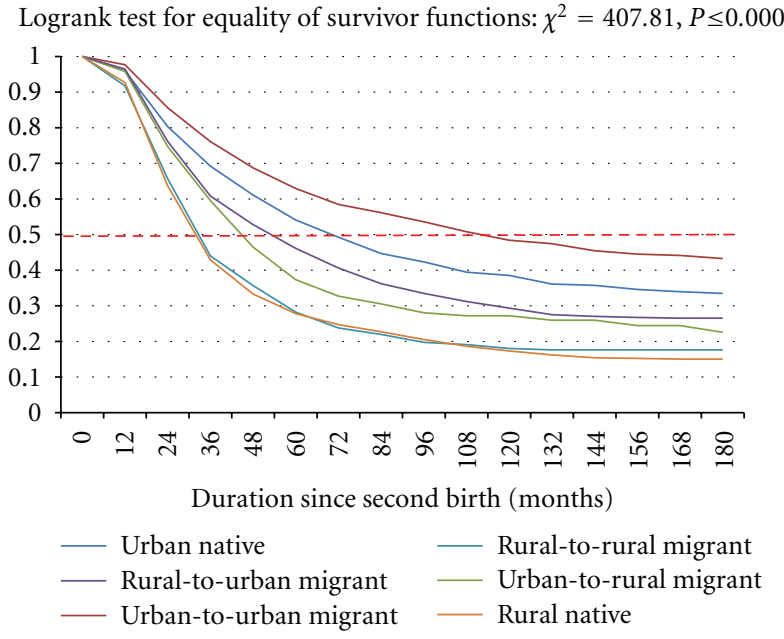

FIGURE 4: Kaplan-Meier survival estimate of the proportion of having third birth since second birth, by migration status.

third birth later than the women in the other categories. The proportion of women having third birth by the end of reproductive ages is also lower among urban natives and urban-to-urban migrants. The pattern of the survival curve of urban-to-rural migrants is similar to the curve of rural natives and rural-to-rural migrants. The level and pattern of the curve of rural-to-rural migrants is between urban natives and rural natives. Survival curves of rural natives and ruralto-rural migrants are almost identical.

The survival curves of third birth by migration status indicates that around 35 percent of rural native and ruralto-rural migrant women have their third child within 2 years after second birth. This percentage decreases to 20 percent among urban natives and 14 percent among urbanto-urban migrant women. One fourth of urban-to-rural and rural-to-urban migrant women have a third child within 2 years. Within the 5 years following the birth of second child, the percentage of women having a third birth exceeds 70 percent among rural natives and rural-to-rural migrant women. The corresponding percentage among urban-tourban migrants is 27 percent and that of urban natives is 46 percent. Fifty four percent of rural-to-urban migrant women and 63 percent of urban-to-rural migrant women have third births within five years following the birth of their second child. Similar to the second birth, percentages of rural-tourban migrant women and urban-to-rural migrant women are closer to the percentages at the place of destination rather than place of origin. Within 10 years following the birth date of second child, only 18 percent of rural native and ruralto-rural migrant women do not have a third child; however, almost half of the urban-to-urban migrant women and 39 percent of urban native women do not have a third child. The percentage of women who do not experience a third birth within 10 years after the second birth among rural-tourban migrants and urban-to-rural migrants is 29 percent and 27 percent, respectively. The highest median third birth interval is observed among urban-to-urban migrant women 


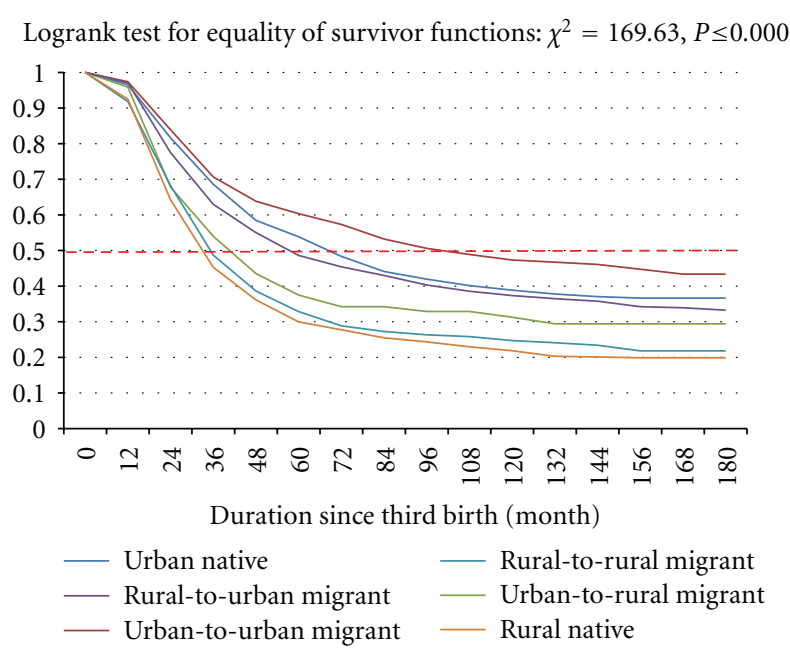

FIgURE 5: Kaplan-Meier survival estimate of the proportion of having fourth birth since third birth, by migration status.

(112 months) and the lowest median is observed among rural natives (32 months).

4.2.4. The Transition to Fourth Birth. High order births are generally unintended, unwanted births. The results of 2003 Turkey Demographic and Health Survey reveals that among three-child mothers just 4 percent want to have another child in the future [1]. This section displays the Kaplan-Meier survival estimates for the transition to fourth birth by all covariates. Kaplan Meier survival estimates indicate that at the national level 26 percent of three-child mothers have their fourth child within 2 years following the third birth (Figure 2). Five years after the third birth, the percentage of women having a fourth child increases to 56 percent, and after 10 years the percentage having a third child increases to 67 percent. By the end of reproductive ages, 30 percent of three-child mothers do not have a fourth child. The median fourth birth interval is measured as 51 months (Table 5).

Figure 5 displays survival curves of the fourth birth by migration status. Survival curves look very similar to that of third birth. Urban-to-urban migrants have their third birth later than all other categories. A notable point is the similarity between survival curves of urban natives and ruralto-urban migrants. The pattern of the survival curve of urban-to-rural migrants is again similar to the curve of rural natives and rural-to-rural migrants. Survival curves of ruralto-rural migrants and rural natives resemble each other.

The survival curves of fourth birth by migration status reveal that approximately 35 percent of rural native and rural-to-rural migrant women have their fourth child within 2 years following the third birth. The corresponding percentages of urban natives and urban-to-urban migrants are 19 and 16 percent, respectively. Thirty-two percent of urbanto-rural migrants and 22 percent of rural-to-urban migrants have fourth child within 2 years after the third birth. Approximately, 7 of every 10 rural native or rural-to-rural migrant women have a fourth child within 5 years following the third birth. This percentage decreases to 46 percent among urban natives and 40 percent among urban-to-urban migrants. Half of the rural-to-urban migrant women have a third child within 5 years after their second birth. The percentage of women having a fourth child within 10 years after a third child exceeds 75 percent among rural natives and rural-to-rural migrants. However, half of the mothers with three children have an additional child among urban-tourban migrants. Correspondingly, the highest median fourth birth interval is observed among urban-to-urban migrants with 100 months. On the other hand, rural natives have the lowest median fourth birth interval.

\section{Discussion and Conclusion}

In this study, the relationship between migration and fertility was analyzed at different levels. First, the relationship was analyzed at the descriptive level. Fertility levels, patterns, and trends of migrants were compared with those of nonmigrants. Second, Kaplan-Meier survival estimates of the transition from first marriage to the first birth, and subsequently to the second, third and, fourth births were presented according to the migration status.

The Kaplan-Meier survival curve estimates revealed that the timing of first births does not differ highly by women's migration status. The shortest median first birth interval is observed among urban native women. This interesting finding was explained with the "compensation effect." As urban native women marry later than their counterparts, they might tend to compensate the time "wasted" by having first child earlier [38]. Kaplan-Meier survival estimates of second and subsequent births provided evidence for differential fertility behaviour by migration status. Considering survival curves of second and subsequent births, we observed that survival curves of rural natives and rural-to-rural migrants are almost identical and those of urban natives and urban-tourban migrants are similar. Urban-to-urban migrants tend to have higher order births later than urban natives and the proportion of women having higher order births is also lower. This situation may be related with different individual characteristics of urban-to-urban migrants, probably they are a selected group having higher education, and the ratio of women working with social security is higher than that of urban native women.

The survival curves of rural-to-urban and urban-torural migrant women are similar to the curves at the place of destination rather than place of origin. This situation reminds us the adaptation hypotheses. As it is well known, while socialization hypothesis emphasizes the importance of childhood environment, adaptation hypothesis underlines the importance of new environment. Dominant values and norms in new environment shape migrants' social and reproductive behaviours. Therefore, migrants' behaviours converge with that of natives in the new environment after a period of time [10-15]. The results suggest that the adaptation hypothesis rather than the socialization hypothesis is more explanatory in Turkey.

In this study, we calculated median ages at first marriage according to the migration status of women (Figure 6) 


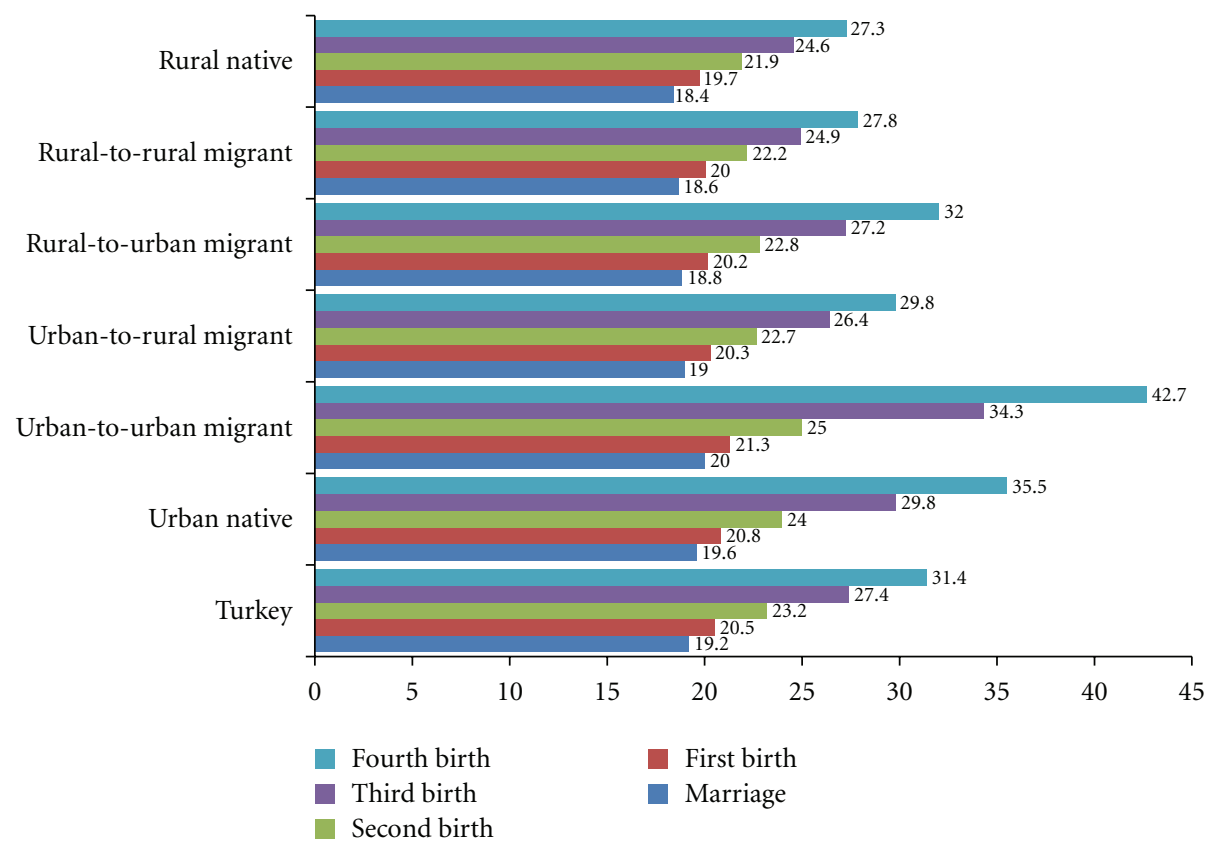

FIGURE 6: Timing of childbearing events by migration status (age of women).

in order to calculate women's age at first, second, and subsequent births, by simply adding median birth intervals to the age at first marriage. Kaplan-Meier survival estimates revealed that, on average, a woman in Turkey marries at age 19.2, becomes mother at age 20.5, has second, third, and fourth child at age 23.2, 27.4, and 31.4, respectively. The results showed that rural native and rural-to-rural migrant women experience all the events related with family formation earlier in their life cycle. On average, they marry around age 18 and have their fourth child at age 27, in other words within 9 years they have four children. However, urban native and urban-to-urban migrant women have their fourth child at ages 36 and 43 , respectively. While rural-to-urban migrant women have their fourth child at age 32 , urban-torural migrant women have fourth child at age 30 . This result shows that lifelong fertility experience of migrants is closer to that of place of destination, rather than place of origin (Figure 6).

Lastly, it is necessary to mention the limitations of the study. The first limitation is related to the data source. Though TDHS-2003 includes a wide range of retrospective questions on birth histories and contraceptive use, most of the background characteristics were not collected with the individual life histories, such as information on migration, employment, and the family cycle. As TDHS-2003 does not provide detailed migration history of women, we could only consider last migration. This limitation also prevented us from considering duration between migration and birth event. In the future, longitudinal data or cross-sectional surveys collecting information on migration and other parallel processes, such as education, employment, marriage, and birth with individual life histories, may provide further deeper insights into the topic. Information on precise timing of migration and fertility events would provide new opportunities to study the interrelationships between them. The THDS-2008 data needs to be discovered in this aspect. In TDHS-2008 women's migration, employment, marriage, and birth experiences were collected with individual life histories. Secondly, in this study we have compared the fertility of migrants and nonmigrants in Turkey at the descriptive level. However, the descriptive analysis has certain limitations. The variations of birth intervals were not standardized by demographic, social, economic, and cultural control variables. Therefore, descriptive analyses provide only the "gross" impact of each variable on fertility. To estimate the standardized birth intensities, event-history methods are needed. Using event-history methods, associations between the probability of having a specific birth, and woman's individual, socio-economic, cultural, and familial characteristics can be explored, and the "net" impact of each covariate can be explored. In the next study, determinants of first, second, third, and fourth births will be investigated using event-history analysis and focusing on migration status of women.

\section{Disclosure}

This study is prepared from unpublished Ph.D. dissertation submitted to Hacettepe University, Institute of Population Studies, Department of Technical Demography in January 2010.

\section{References}

[1] Hacettepe University Institute of Population Studies (HUIPS), 2003 Turkey Demographic and Health Survey, Hacettepe University, Ankara, Turkey, 2004. 
[2] D. Goldberg, "The fertility of two generation urbanites," Population Studies, vol. 12, no. 3, pp. 214-222, 1959.

[3] D. Goldberg, "Another look at the Indianapolis fertility data," Milbank Memorial Fund Quarterly, vol. 38, pp. 23-36, 1960.

[4] O. D. Duncan, "Farm background and differential fertility," Demography, vol. 2, pp. 240-249, 1965.

[5] R. Freedman and D. P. Slesinger, "Fertility differentials for the indigenous non-farm population of the United States," Population Studies, vol. 15, no. 2, pp. 161-173, 1961.

[6] N. J. McGirr and C. Hirschman, "The two generation urbanite hypothesis revisited," Demography, vol. 16, no. 1, pp. 27-35, 1979.

[7] I. Rosenwaike, "Two generations of Italian in America: their fertility experience," International Migration Review, vol. 7, no. 3, pp. 271-280, 1973.

[8] E. H. Stephen and F. D. Bean, "Assimilation, disruption and the fertility of Mexican-origin women in the United States," International Migration Review, vol. 26, no. 1, pp. 67-88, 1992.

[9] J. R. Kahn, "Immigrant selectivity and fertility adaptation in the United States," Social Forces, vol. 67, no. 1, pp. 108-128, 1988.

[10] G. C. Myers and E. W. Morris, "Migration and fertility in Puerto Rico," Population Studies, vol. 20, no. 1, pp. 85-96, 1966.

[11] S. Goldstein, "Interrelations between migration and fertility in Thailand," Demography, vol. 10, no. 2, pp. 225-241, 1973.

[12] V. A. Hiday, "Migration, urbanization, and fertility in the Philippines," International Migration Review, vol. 12, no. 3, pp. 370-385, 1978.

[13] S. C. Farber and B. S. Lee, "Fertility adaptation of rural-tourban migrant women: a method of estimation applied to Korean women," Demography, vol. 21, no. 3, pp. 339-345, 1984.

[14] B. S. Lee and L. G. Pol, "The influence of rural-urban migration on migrants' fertility in Korea, Mexico and Cameroon," Population Research and Policy Review, vol. 12, no. 1, pp. 3-26, 1993.

[15] H. Kulu, "Migration and fertility: competing hypotheses reexamined," European Journal of Population, vol. 21, no. 1, pp. 51-87, 2005.

[16] State Institute of Statistics (SIS), The Population of Turkey, 1923-1994 Demographic Structure and Development, State Institute of Statistics Prime Ministry Republic of Turkey, Ankara, Turkey, 1995.

[17] State Institute of Statistics (SIS), 2000 Census of Population Social and Economic Characteristics of Population, State Institute of Statistics, Ankara, Turkey, 2000.

[18] İ. Koç, M. A. Eryurt, T. Adalı, and P. Çağatay, Türkiye'nin Demografik Dönüşümü: Doğurganlık, Aile Planlaması, AnneÇocuk Sağhı̆̆ı ve Beş Yaş Altı Ölümlerdeki Değiş̧imler: 19682008, Hacettepe University, Ankara, Turkey, 2010.

[19] Turkish Statistical Institute (TURKSTAT) (Download date: 29.03.2012) Population Projections and Estimations-Demographic Indicators, http://www.tuik.gov.tr/VeriBilgido?tb_id= 39\&ust_id=11.

[20] N. Levine and S. Uner, Population Policy Formation and Implementation in Turkey, Hacettepe University, Ankara, Turkey, 1978.

[21] S. Üner, Türkiye Nüfusu: Boyutlar Sorunlar Yorumlar, HUIPS, Ankara, Turkey, 1984.

[22] TÜSİAD, Türkiye'nin Fırsat Penceresi Demografik Geçiş ve İzdüşümleri, Türk Sanayicileri ve İşadamları Derneği, İstanbul, Turkey, 1999.
[23] E. Franz, Population Policy in Turkey, Deutches Orient-lnstitut, Hamburg, Germany, 1994.

[24] A. Gedik, "Internal migration in Turkey, 1965-1985: test of some conflicting findings in the literature," Working Paper, The Australian National University, Canberra, Australia, 1996.

[25] T. Kocaman, “Türkiye'de İç göçler-İller arası kır-kent göçleri ve göç edenlerin nitelikleri (1965-1990)," in Türkiye'de Tarımsal Yapı ve Istihdam, T. Bulutay, Ed., DPT, Ankara, Turkey, 1998.

[26] A. İçduygu and İ. Sirkeci, “Cumhuriyet dönemi Türkiye'sinde Göç hareketleri," in 75 Yılda Köylerden Şehirlere, O. Baydar, Ed., Türk Tarih Vakfi, İstanbul, Turkey, 1999.

[27] Turkish Statistical Institute (TURKSTAT), Census of Population, Migration Statistics, Ankara, Turkey, 2000.

[28] Hacettepe University Institute of Population Studies (HUIPS), Survey on Migration and Internally Displaced Persons in Turkey, Hacettepe University, Ankara, Turkey, 2006.

[29] F. Özbay and B. Yücel, "Türkiye'de göç hareketleri, devlet politikaları ve demografik yapı," in Nüfus ve Kalkınma: Göç, Ĕ̆itim, Demokrasi, Yaşam Kalitesi, F. Özbay, B. Yücel, and İ. Sezai, Eds., Hacettepe University Institute of Population Studies, Ankara, Turkey, 2001.

[30] G. Rodriguez and J. N. Hobcraft, "Illustrative analysis: life table analysis of birth intervals in Colombia," The Haugue Netherlands, World Fertility Survey Scientific Reports 369, 1980.

[31] G. Feeney and Jingyuan Yu, "Period parity progression measures of fertility in China," Population Studies, vol. 41, no. 1, pp. 77-102, 1987.

[32] United Nations, Family-Building and Family Planning Evaluation, Department of Economic and Social Affairs, Population Division. United Nations, New York, NY, USA, 1997.

[33] H. P. Blossfeld, K. Golsch, and G. Rohwer, Techniques of Event History Modeling Using Stata. New Approaches to Causal Analysis, Erlbaum, Mahwah, NJ, USA, 2007.

[34] E. L. Kaplan and P. Meier, "Nonparametric estimation from incomplete observations," Journal of the American Statistical Association, vol. 53, pp. 457-481, 1958.

[35] N. Mantel, "Evaluation of survival data and two new rank order statistics arising in its consideration," Cancer Chemotherapy Reports. Part 1, vol. 50, no. 3, pp. 163-170, 1966.

[36] D. Schoenfeld, "The asymptotic properties of nonparametric tests for comparing survival distributions," Biometrika, vol. 68, no. 1, pp. 316-319, 1981.

[37] D. Harrington, Linear Rank Tests in Survival Analysis Standard Article, Encyclopedia of Biostatistics, Wiley Interscience, 2005.

[38] Y. Hong, "Marital decision-making and the timing of first birth in rural China before the 1990s," Population Studies, vol. 60, no. 3, pp. 329-341, 2006.

[39] G. Feeney and Wang Feng, "Parity progression and birth intervals in China: the influence of policy in hastening fertility decline," Population \& Development Review, vol. 19, no. 1, pp. 61-101, 1993.

[40] S. Yavuz, "Completing the fertility transition: third birth developments by language groups in Turkey," Demographic Research, vol. 15, article 15, pp. 435-460, 2006. 


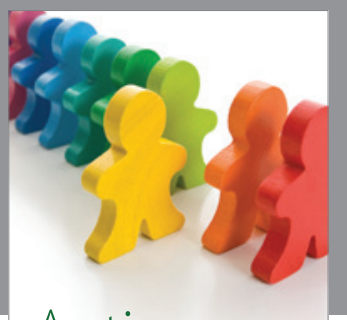

Autism

Research and Treatment
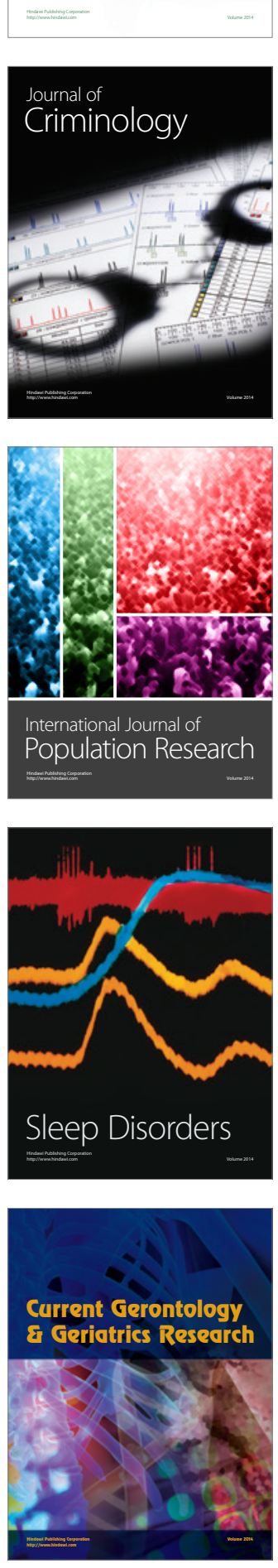
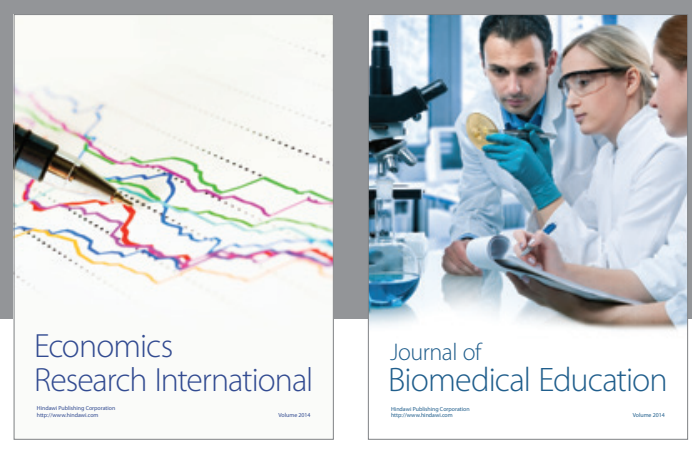

Journal of

Biomedical Education

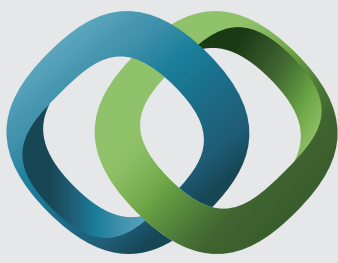

\section{Hindawi}

Submit your manuscripts at

http://www.hindawi.com
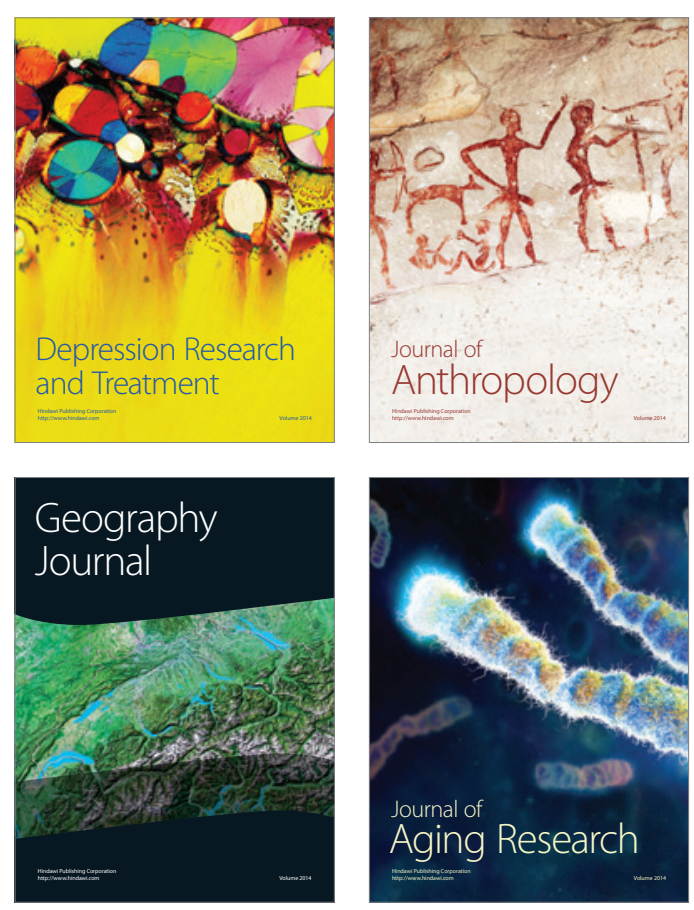

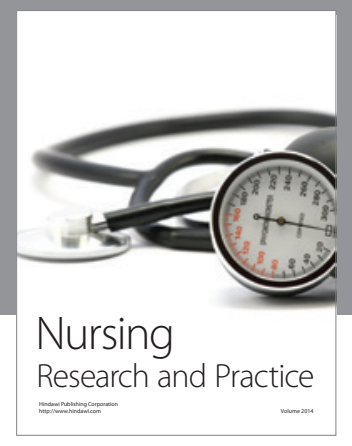

Nursing

Research and Practice

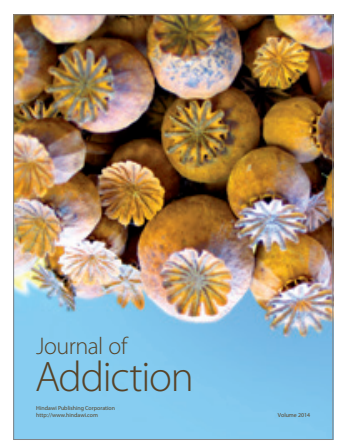

Child Development

Research

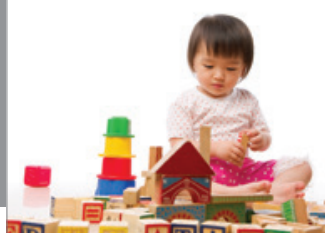

迥
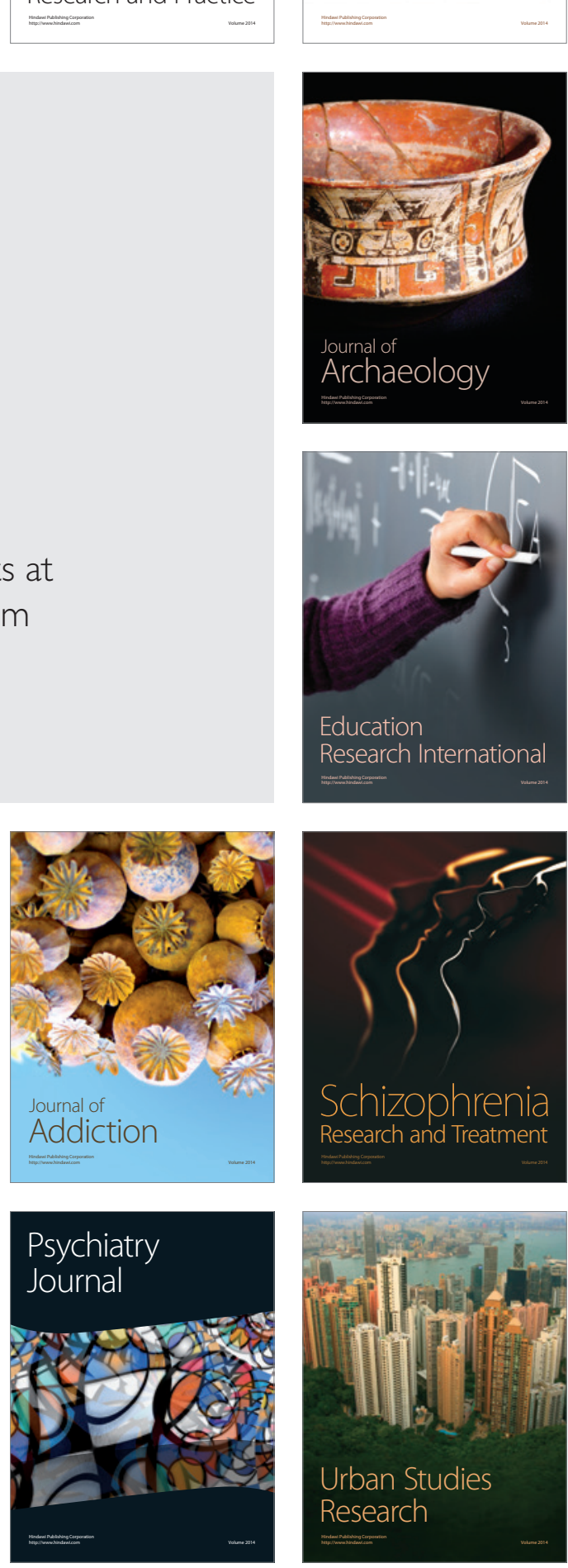